\title{
Mining Technologies Innovative Development: Economic and Sustainable Outlook
}

\author{
Sergey Zhironkin ${ }^{1,2,3, *(D)}$ and Dawid Szurgacz ${ }^{4}$ (D) \\ 1 Institute of Trade and Economy, Siberian Federal University, 79 Svobodny Avenue, \\ 660041 Krasnoyarsk, Russia \\ 2 School of Core Engineering Education, National Research Tomsk Polytechnic University, 30 Lenina Street, \\ 634050 Tomsk, Russia \\ 3 Department of Engineering and Economy, Mezhdurechensk Branch, T.F. Gorbachev Kuzbass State Technical \\ University, 36 Stroiteley Street, 652881 Mezhdurechensk, Kemerovo Region, Russia \\ 4 Center of Hydraulics DOH Ltd., 41-906 Bytom, Poland; dawidszurgacz@doh.com.pl \\ * Correspondence: zhironkinsa@kuzstu.ru
}

check for updates

Citation: Zhironkin, S.; Szurgacz, D. Mining Technologies Innovative Development: Economic and Sustainable Outlook. Energies 2021, 14, 8590. https://doi.org/ 10.3390/en14248590

Received: 24 November 2021 Accepted: 11 December 2021 Published: 20 December 2021

Publisher's Note: MDPI stays neutral with regard to jurisdictional claims in published maps and institutional affiliations.

Copyright: (c) 2021 by the authors. Licensee MDPI, Basel, Switzerland. This article is an open access article distributed under the terms and conditions of the Creative Commons Attribution (CC BY) license (https:// creativecommons.org/licenses/by/ $4.0 /)$.

\section{Introduction}

Today science faces the task of ensuring the innovative development of the mineral extractive sector of the economy in resource-rich countries, in the context of unfolding two opposite trends. The first trend is the growing volatility of commodity prices caused by increased competition both between the largest mining companies and between interchangeable types of raw materials, traditional and alternative energy. The second trend is the growing long-term demand for mineral resources, which is unabated due to the world population growth and the convergence of developed and developing countries.

The volatility inherent to the commodity market in the past two years has been exacerbated by an unprecedented exogenous factor-the COVID-19 pandemic, which caused a reduction in global industrial output and labor hours equivalent to the loss of 195 million jobs in the global labor market [1]. As a result of the pandemic in 2020, prices for such raw materials as nickel, copper and coal showed a double-digit decline. Most of the forty largest mining companies have lowered their production forecasts by $7-9 \%$, while their net profit and total market capitalization have decreased by almost two times [2]. In such conditions, innovative development of mining technologies is the only way to ensure cost reduction and, thereby, the long-term stability of mining companies and to avoid resource crises.

The innovative development of mining technologies is also driven by the need for saturation the long-term demand for raw materials, the growth of which is attributed by experts to the "new industrialization" in BRICS countries, North Africa, South America, as well as to the large-scale digitalization and development of electric transport [3]. Moreover, the two aforementioned trends in the development of the global mining sector can be described as converging, due to the stimulating effect of climatic and pandemic factors on the long-term demand for raw materials. Consequently, we can talk about a consensus of views regarding the long-term prospects for demand for minerals, both in developed and developing countries, which is a positive factor in the development of technological modernization of the mining industry. This is of particular importance for the economies of the countries leading the extraction of raw materials on their continents [4].

At the same time, in the last decade, there has been a decrease in labor productivity in the mineral extractive sector, among the reasons for which one can single out the achievement of the limit of technologies and the specific capacity of equipment, the "closure" of the chains using raw materials within the framework of existing industries. In such conditions, an increase in the specific capacity of equipment for the extraction of minerals inevitably turns into an increase in capital and operating costs, which reduces the interest of investors in the modernization of the industry as a whole. On the contrary, there is a 
great need to improve technologies for automating mining processes, ensuring labor safety in the complex extraction of minerals. This is dictated by the peculiarities of mining in the 21st century, such as the depletion of rich deposit reserves, the need to develop poor and hard-to-reach deposits, the limited mineral resources for enrichment, the need to solve environmental problems and as a result, the increase in costs.

The extraction of certain types of mineral raw materials directly determines the possibilities of promoting in society the values created with the help of Industry 4.0 technologies. For example, the growth rate of demand for copper, without which it is impossible to develop high-tech industries and energy, has doubled over the past 20 years-from 12 to 24 million tons, with the prospect of growth by 2035 by another $50 \%$ [5]. In general, humanity cannot stop extracting mineral resources, but it must use the possibilities of their complex extraction and waste-free processing. To solve this problem, it is necessary to integrate the efforts of the scientific community, mining companies, national states and the public in a "triple" and "quadruple" helix, in which innovative technologies will be introduced in a timely manner for the benefit of not only mining companies, but also the whole society. This, in turn, should emphasize the desire of the mining scientific community to expand the range of decision-making centers in the process of developing discussions regarding the future innovative development of the mining industry.

Thus, the development of innovative mining technologies should provide an answer to a number of challenges facing the mining industry.

The first challenge is the need for a radical increase in labor productivity in the mineral extractive sector in the process of improving mining equipment and technologies. Over the past two decades, mining companies have been actively investing in the implementation of digital technologies of Industry 4.0 (automated and unmanned equipment, integration of exploration and geophysical surveys, design of mining enterprises, environmental modeling, etc.). However, for a full-scale technological transition throughout the mining industry, it is necessary to modernize traditional extractive technologies "inherited" from the 20th century. In other words, despite the amazing opportunities that digital technologies offer for reducing costs, increasing productivity and improving labor safety and technogenic security, these benefits cannot be realized without the innovative development of mining technologies and processes themselves. Innovative modernization of the mining industry means profound changes in its technological core, including the transition to integrated extraction of reserves and waste-free technologies, comprehensive replacement of obsolete equipment incompatible with digitalization and minimization of the risks associated with failures of production systems.

The second challenge facing the innovative development of the mining industry is the transition to geotechnology consistent with Mining 4.0. The current stage of geotechnology development is based on the return of mining into the category of high-tech industries, thanks to the expansion of the use of unmanned robotic complexes in underground and surface mines, digital telemetry, machine-to-machine Internet communications and artificial intelligence in the analysis of mining technology and design information. Such "smart mining" is associated with a more accurate assessment of mineral reserves based on current prices and costs, optimization of material flows, labor costs, equipment performance, advanced forecasting of equipment failures, virtual digital training of mining personnel and the creation of fully unmanned sites. The research of innovative geotechnology (underground, opencast, construction) aimed at improving drilling and blasting, excavation and loading, transport operations, planning and operational management of processes must go side by side with Mining 4.0 so that mining enterprises of the future can completely exclude people from mineral extraction processes. The future of geotechnology development lies in the highest level of coordination of equipment complexes and flexibility in managing technological processes in mines, which should make mining profitable at any level of prices and demand for raw materials.

The third challenge is "green mining", which means the diffusion of innovations originating in related industries into the mining industry. Today, the prevailing opinion 
is that the extraction of minerals as a natural-technological interaction is a divergent process that alienates a person from nature, despite the expanding range of nature-saving technologies [6]. At the same time, governments in many countries are tightening environmental requirements for mining companies, which negatively affects their profitability. Therefore, the innovative development of "green" mining should be a convergent process that brings together the production and consumption of minerals on the one hand, and the preservation of the environment on the other. Such opportunities for mining-andenvironmental convergence are provided by a complete transition to land and water-saving technologies, recycling of water and other resources, and complete extraction of useful components in several cycles. This is the only way to solve the problem of reducing the technogenic impact on the environment from mining operations and to save used resources by reducing the costs of companies. This mainstream implementation of environmental innovations in the mining industry will allow it to develop in the context of transitioning to decarbonization - the reduction of greenhouse gases by mining enterprises in order to reduce the risks associated with climate change.

The fourth challenge facing the innovative development of mining is improving labor safety and avoiding social consequences and economic losses caused by industrial accidents. Despite the fact that mining is associated with a large number of risk factors for accidents that threaten the lives of many people, and not completely predictable processes in the Earth's crust, there is a consensus that the root cause of emergencies (gas explosions, landslides, rock bumps, rock bursts, flooding, etc.) is the human factor. At the same time, today, the role of people in the extraction of minerals is limited to the operating and maintenance of equipment with a highly specific capacity, which, on the one hand, can harm employees, and on the other, cause economic losses in the case of breakdowns due to the fault of personnel. Therefore, the development of technologies for ensuring labor safety at mining enterprises is closely related both to innovations in mining engineering and geotechnology and in the organization of mining operations. At a fundamental level, the creation of innovations in labor safety in the mining industry is associated with predicting the action of threats and the factors that form them, using "Smart Sensors" and "Cloud Analysis" of data on the state of rock arrays, equipment and work processes.

All of the listed challenges of the mining industry's innovative development require a technological breakthrough in the extraction of minerals based on a wide range of fundamental and applied research. The purpose of this Special Issue is to highlight the advanced opinions of leading scientists on the ways and prospects of the progress of mining technologies. As Guest Editors, we got a chance to contribute to the polemic regarding the innovative development of mining technologies, and to make sure of the necessity to involve the leading research schools of the world of mining science.

We welcome a positive response from the world mining science community, accompanied by nineteen high-quality articles in quantity, that confirm a sustained interest in the innovative development of mining technologies, as well as in reducing the manmade impact on the environment and improving occupational safety. Safe, "smart" and environmentally-friendly mining is the core value promoted by this Special Edition. All articles published in this Special Issue address a broad range of mining technologies innovative development, pushing the boundaries of mining science and highlighting the complex nature of securing a prosperous future for the mining sector.

The next section is devoted to a review of the research papers published in the 'Energies' Special Issue "Mining Technologies Innovative Development", reflecting the above-mentioned challenges.

\section{Special Issue Articles' Short Review}

Articles published in this Special Issue as a part of Energies can be grouped in accordance with their thematic areas, which correspond to the aforementioned challenges for the innovative development of mining technologies. 
With regard to the first challenge - the improvement of mining equipment in order to radically increase labor productivity in the mineral resource sector-eight articles address innovations in the development of tumbling and ball mills, powered roof supports, conveyor belts and drives maintenance, in-engine oil systems for heavy-duty equipment, drilling tools and equipment selection for surface mining. Their provisions are connected with increasing the efficiency of mining equipment as a key factor of the productivity of mining enterprises.

The article by Góralczyk et al. [7] provides an overview of innovations in the operating of the comminution process in tumbling mills from the point of view of reducing energy consumption. The authors note that despite a significant number of studies carried out, in real industrial practice, the energy efficiency of the comminution process in tumbling mills remains low in relation to the optimal level of ore particle size for beneficiation, the efficiency of which depends on reducing the amount of waste. The relevance of the presented study lies in the fact that the modernization of heavy equipment is high-cost; process optimization using special models and control systems is the most preferred solution to reduce energy consumption. Therefore, research is currently focused on new methods of performance analysis, as well as control of internal dynamics.

Szurgacz et al. [8] presented a methodology for tests and assessment of powered roof support, which determines the possibility of automatic control during coal mining from deep seams. The powered roof support system has three main parts: a shearer, a scraper conveyor and a powered roof support. The article reflects a comprehensive methodology for estimation of the prospects of a powered roof support in real conditions, combining four directions, and presents the results of tests, certification and executive documentation, allowing determination of the prospects for the potential use of the system in the future. The conclusions drawn from the results of the presented study are a valuable source of information for the design of mining equipment systems in terms of improving the efficiency and safety of labor.

Bajda et al. [9] presented new results from tests of the strength parameters of conveyor belt splices carried out in laboratory and industrial conditions, which indicated the reasons for the decrease in strength. A conveyor belt, which is critical to the reliable and efficient operation of equipment, is the most expensive and least durable element, so repairing belt damages is important to ensure the smooth transport of bulk materials. A conveyor belt consists of a core, covers and edges, and cutting of the core causes concentrated stresses of the belt splices. During a splicing procedure, parts of a belt are joined with each other. In view of the above, the analysis performed by the authors made it possible to establish that the strength of conveyor belt splicing decreases mainly due to improper preparation of the spliced surfaces and various mechanical properties of the belts. The value of the conclusions obtained by the authors lies in the ability to increase the strength of conveyor belt splicing without the use of additional equipment and materials.

Bortnowski et al. [10] investigated models of copper ore ball mill drive systems in order to come up with a solution to reduce the energy intensity of starting a filled mill. The authors took as a basis two designs of drive systems with relatively high efficiency-lowspeed synchronous motor with permanent magnets without a gearbox, and asynchronous high-efficiency motor with a gearbox and a fluid coupling. The average energy consumption per unit mass of crushed material and the hourly electricity consumption were taken as criteria for evaluating the energy consumption of copper ore ball mill drive systems. To analyze the data obtained, the Monte Carlo method was applied, using which it was revealed that the least energy-intensive solution for starting a copper ore ball mill is to use a drive with a low-speed synchronous motor with permanent magnets.

Patyk et al. [11] propose a new methodology for the selection of mining equipment for surface mining, based on the adoption of multi-criteria decisions in the design of sections, allowing optimization of the excavation and loading transport processes in open pits, taking into account operating costs. The authors developed a universal set of criteria for the selection of mining equipment, including those taking into account technical parame- 
ters and the experience in mining operations accumulated by the mining company. The study used the ELECTRE III ranking method to select alternative options for choosing mining equipment. The equipment selection methodology obtained by the authors can be applied in surface mining sections with similar mining conditions. The authors associate further prospects of this study with the formation of universal criteria for choosing mining equipment, taking into account data on the state of the environment and the quality of minerals.

The article by Szurgacz et al. [12] presents the results of a thermal imaging study of the state of the conveyors' power units of the main system for transporting coal from a longwall. The study used a non-contact method for measuring infrared radiation; subsequently, the obtained thermograms were analyzed to compare the temperature distribution, taking into account the operating time of the conveyors. As a result of the application of the proposed method, changes in the thermal state of the operating conveyor were identified, indicating a possible malfunction of the probability of fire, which allows early maintenance and minimizes the risk of their occurrence. The obtained data on the thermal state of the conveyor belt drive will help to improve the maintenance of the mine.

The article by Grzesiek et al. [13] presents an innovative method of data analysis for structure breakpoint detection in engine oil pressure data, which makes it possible to quickly predict equipment breakdowns. The presented method is based on the authors' findings showing that when a degradation process occurs, there is a change in engine oil pressure. As a result, the authors proposed an original method of statistical processing and analyzing data, which are transformed into a nearly monotonic function that can describe the process of changing the regime within the process. The use of the proprietary technique will allow for removing ambiguity in oil pressure analysis and improve its visualization, which, in turn, will simplify the procedure and increase the accuracy of diagnostics of mining equipment failures.

Bazaluk et al. [14] analyzed the constructive, technological and operational methods of increasing the productivity of the drilling tool, which is necessary to enlarge the volume of drilling and increase the production of hydrocarbons. The article presents a new analytical model of the interaction of a drill bit with a well, which takes into account the effect of imperfections in the manufacture of a bit on its strength. As a result of the study, a significant lateral force was identified that arises due to manufacturing errors and presses the drill bit against the borehole wall, which also depends on the material from which the drilling tool is made. The authors found that a geometrical imperfection of the drill bit has a minimal effect on the drill pipe system based on carbon fiber composite material, and this effect is maximized in steel drill pipes. The research conducted allows us to determine the permissible errors in the manufacturing of a drill bit to ensure its safe operation.

With regard to the second challenge- the innovative development of geotechnology up to the level of Mining 4.0-six articles were published devoted to the innovative technology of liquid hydrocarbons production, modeling the ventilation process of mines, studying the stability of mine workings and introducing digital technologies in open pit mining. The provisions of these articles are connected with increasing the efficiency of mining operations and the implementation of Mining 4.0.

Bazaluk et al. [15] presented the results of their study of innovative technology for the production of liquid hydrocarbons, which makes it possible to intensify this process by increasing the productivity of the borehole with an increase in the area of its filtering surface. The innovation presented in the author's study consists of the formation of circular cuts of a large diameter perpendicular to the borehole axis for the destruction of the rock mass between them as a result of the application of static or dynamic loads by the mass of the drilling tool. The main advantage of the proposed innovative technology for the intensification of hydrocarbon fluid production is low energy consumption for expanding the diameter of the well. The article presents a special tool developed by the authors for drilling annular notches and gives the results of a numerical analysis of the expansion of the borehole diameter in reservoir rocks, which increases in twenty times. 
Janus et al. [16] published in their article the results of numerical modeling of the airflow in mine workings, innovative due to the rejection of the widespread simplificationthe adoption of a constant geometry of the working model along its entire length. Instead, the authors used the exact reproduction of the sections of the modeled mine working. The author's method is based on laser scanning of mine workings with multi-point velocity measurements in selected cross-sections, and on the modeling of SAS turbulence. The methodology proposed by the authors made it possible to simplify the flow analysis and modeling process significantly, while its results are quite consistent with measurements on the site.

In an article by Adach-Pawelus et al. [17], the problem of stability in a group of headings in the copper ore mines was considered (by the example of the Legnica-Glogow Copper Belt), and a new method of application of a roof bolting system was proposed to protect headings driven in unfavorable conditions in a high horizontal stress field. An analysis of stability was performed by authors for a group of four headings in the PolkowiceSieroszowice mine using the finite element method. The Hoek-Brown classification was used to determine rocks parameters (RocLab 1.0 software); the measuring device was a CSIRO HI probe, and in-situ measurements were used to identify stress field parameters. The authors concluded that the stability of headings depends on the direction of the maximum horizontal stress component, the shape, depth and cross-section surface area of the heading, as well as on the surrounding rock's stress and strain parameters.

Wajs et al. [18] presented an innovative method for obtaining and integrating digital data for the accurate inventorying of surface mines, including the physical and technical parameters of overburden and mineral, mining and geometric data on its occurrence and mine workings, the boundaries of support pillars and buffer zones, the success of mining operations in relation to established boundaries, the impact of mining operations on the land, documentation of the hazards of landslides and the environmental impact of mining operations, etc. The implementation of the author's method is presented in the form of the results of a measurement experiment carried out at the Mikoszów granite surface mine (Poland) using mobile LiDAR systems, combining sensors with automatic and global navigation on a mobile platform, which generates a precise 3D cloud of geospatial points. In the future, the implementation of the method presented by the authors should contribute to using the technological level of Industry 4.0 in surface mining.

Wodecki et al. [19] proposed a simple, reliable system for the automatic identification of drilling cycles in the process of monitoring the work of heavy-duty drilling rigs. Despite the fact that monitoring of drilling processes is widely used for analyzing the physical and technical properties of rocks and assessing bit wear, modern on-board monitoring and automatic data analysis systems are not highly reliable or versatile. In order to overcome these shortcomings, the article discusses innovative hardware and software monitoring based on electro-acoustic measurements, thereby identifying the stage of preliminary drilling with an intermediate amplitude, which masks real drilling cycles. The tests of the proposed monitoring system installed on the drilling rig in the landfill conditions consisted of comparing the data with that of the on-board monitoring system installed by the equipment manufacturer. The test results indicate the high efficiency and reliability of the authors' system.

Borkowski [20] presented a new vision of the problem of grinding copper ore with the use of a high-pressure water jet. The results of the published study indicate that the effect of the grinding method proposed by the author allows increasing the specific surface area of copper ore particles significantly, which, in turn, simplifies its further processing. The analysis of the efficiency of grinding copper ore by the water jet method in comparison with mechanical grinding (in a planetary ball mill) according to the criterion of specific energy consumption and the efficiency of the grinding process showed that the use of a high-pressure water jet gives lower energy absorption. The results of the study were supplemented with a provision on the relationship between the efficiency of grinding 
copper ore and the strength characteristics of the host rock; in particular, the highest efficiency was found for sandstone and shale ores.

The third challenge facing the innovative development of mining technologies"green mining" - is reflected in the article by Pactwa et al. [21], in which traditional and new approaches to the integrated development of subsoil are analyzed, and post-mining is highlighted as the most advanced method of reclamation of mine workings, taking into account environmental, social and economic results. The prospects for the environmental and energy policy of the European Union are associated with a reduction in the number of mines; therefore, the authors argue the need for advanced planning of their future reclamation. For this purpose, the article analyzes the strengths and weaknesses of the new reclamation methods, in comparison with the traditional method of filling or flooding the worked-out underground space at the end of mining. The authors took into account the views of a number of stakeholder groups regarding the feasibility of reusing underground structures and concluded in favor of preserving the mine infrastructure and using it in post-mining as being consistent with the imperatives of sustainable development.

The next four articles are devoted to the fourth challenge-improving labor safety at mining enterprises and reducing social-and-economic losses caused by accidents. These articles consider the development of innovative technologies to reduce the risk of sudden methane emissions from coal seams and improve mobile sensors, UAV application in search and rescue actions in the mines, and geomechanics. The provisions of these articles are connected with achieving the target of zero fatal accidents caused by technogenic factors in mines.

Tutak et al. [22] presented a new approach to the analysis of mine ventilation impact on the risk of methane release and coal combustion. The authors consider the selection of a ventilation system that is suitable for a given coal mining area. The article considers the case of reconstruction of the entire ventilation system of the active section of the longwall, with the transition from a U-type to Y-type ventilation. Following the research presented in the article, an important conclusion was made regarding the use of a Y-type ventilation system, ensuring safety and efficiency in areas with a high risk of methane emissions, while reducing safety due to the spontaneous combustion of coal (which is not typical for U-type ventilation). The research results presented in the article significantly expand knowledge in the field of increasing the efficiency of ventilation in underground workings and providing safety in underground coal mining.

Zietek et al. [23] consider the prospects of introducing an innovative air quality measurement system using portable personal devices to report hazardous gas concentrations in deep mines, which is the cornerstone of safe mining. This system is based on the use of inexpensive microcontrollers and gas analyzers, as well as on the use of common models of smartphones for the calculation and graphical display of results. The existing systems of air hazard evaluations, despite their availability, do not allow for storing the data received from each miner during the shift and require expensive equipment for their analysis. The system proposed by the authors is devoid of these shortcomings. The tests monitoring this system at a mine located in Poland showed very encouraging results.

Zimroz et al. [24] published the results of a study on an innovative way to conduct search and rescue operations in deep mines using unmanned aerial vehicles (UAVs) that are able to locate victims in an accident who are unable to move or give a signal. The authors developed and presented a method for the automatic processing of an acoustic signal to detect a specific sound-a human voice-taking into account noise, including that from the UAVs. The method proposed in the article is based on the time-frequency representation and measurement of the distance between the UAV noise and the obtained data. The article reflects the results of two laboratory experiments of the method proposed by the authors and one experiment carried out in the mine. During the experiments, satisfactory results were obtained, confirming the effectiveness of the innovative method of search and rescue actions in an underground mine proposed by the authors. 
Dwornik et al. [25] proposed a new method for the automatic detection of disturbances in the Earth's surface, applicable in clusters of intensive mining, based on SAR interferograms. The authors describe the procedures and results of the application of coherence and entropy and the spatial distribution of the interferogram phase, which were applied within a field area in mining areas in southern Poland (based on SAR Sentinel-1 images). Comparison of the results of applying the proprietary method with the results obtained by the method based on circular Gabor filters showed that the detection rate for the proprietary method lies within 34-83\%, compared to $30-53 \%$ for the method based on Gabor filters. This indicates a significant improvement in the methods of detecting disturbances of the Earth's surface, as carried out by the authors.

\section{Conclusions}

The articles published in the Special Issue "Mining Technologies Innovative Development" cover the main challenges important for future prospects of subsoil extraction as a public effective and profitable business, as well as technologically advanced industry. In the near future, the mining industry must overcome the problems of structural changes in raw material demand and raise the productivity up to the level of high-tech industries to maintain profits. This means the formation of a comprehensive and integral response to such challenges as the need for innovative modernization of mining equipment and an increase in its reliability, the widespread introduction of Industry 4.0 technologies in the activities of mining enterprises, the transition to "green mining" and the improvement of labor safety and avoidance of man-made accidents. The answer to these challenges is impossible without involving a wide range of the scientific community in the publication of research results and the exchange of views and ideas.

To solve the problem, this Special Issue has combined the works of researchers from the world's leading centers of mining science on the development of mining machines and mechanical systems, surface and underground geotechnology, mineral processing, digital systems in mining, mine ventilation and labor protection, in geo-ecology. A special place among the articles in the Special Issue is given to the post-mining technologies research.

We associate the further advancement of scientific thought in the field of innovative development of mining technologies, on the one hand, with deepening research in the areas of searching for answers to the key challenges facing the mining industry. On the other hand, we are confident that future Special Issue of Energies, devoted to innovative development in mining technologies, will help consolidate and popularize the ideas of scientists and research teams from the world's leading mining countries, including Poland, the Russian Federation, China and Australia.

Author Contributions: All authors contributed equally to this work. All authors have read and agreed to the published version of the manuscript.

Funding: This research received no external funding.

Institutional Review Board Statement: Not applicable.

Informed Consent Statement: Not applicable.

Conflicts of Interest: The authors declare no conflict of interest.

\section{References}

1. International Labour Organization. COVID-19 and the World of Work. Available online: https://www.ilo.org/global/topics/ coronavirus/lang--en/index.htm (accessed on 15 November 2021).

2. Mine 2020. Resilient and Resourceful: PwC's 17th Annual Review of Global Trends in the Mining Industry. Available online: https://www.pwc.com/gx/en/industries/energy-utilities-resources/publications/mine-2020.html (accessed on 15 November 2021).

3. OECD. How Exports of Mineral Commodities Contribute to Economy-Wide Growth. Available online: https://www.oecd.org/ trade/topics/trade-in-raw-materials / (accessed on 15 November 2021).

4. Trenberth, K. Earth's Global Energy Budget. Bull. Am. Meteorol. Soc. 2009, 90, 311-323. [CrossRef]

5. Dong, D.; Tukker, A.; Van der Voet, E. Modeling copper demand in China up to 2050. J. Ind. Ecol. 2019, 23, 1363-1380. [CrossRef] 
6. Engebretsen, R.; Brugger, F. Divergent corporates: Explaining mining companies divergent performance in health impact assessments. Resour. Policy 2021, 74, 102355. [CrossRef]

7. Góralczyk, M.; Krot, P.; Zimroz, R.; Ogonowski, S. Increasing Energy Efficiency and Productivity of the Comminution Process in Tumbling Mills by Indirect Measurements of Internal Dynamics_An Overview. Energies 2020, 13, 6735. [CrossRef]

8. Szurgacz, D.; Zhironkin, S.; Cehlár, M.; Vöth, S.; Spearing, S.; Liqiang, M. A Step-by-Step Procedure for Tests and Assessment of the Automatic Operation of a Powered Roof Support. Energies 2021, 14, 697. [CrossRef]

9. Bajda, M.; Hardygóra, M. Analysis of Reasons for Reduced Strength of Multiply Conveyor Belt Splices. Energies 2021, 14, 1512. [CrossRef]

10. Bortnowski, P.; Gładysiewicz, L.; Król, R.; Ozdoba, M. Energy Efficiency Analysis of Copper Ore Ball Mill Drive Systems. Energies 2021, 14, 1786. [CrossRef]

11. Patyk, M.; Bodziony, P.; Krysa, Z. A Multiple Criteria Decision Making Method to Weight the Sustainability Criteria of Equipment Selection for Surface Mining. Energies 2021, 14, 3066. [CrossRef]

12. Szurgacz, D.; Zhironkin, S.; Vöth, S.; Pokorný, J.; Spearing, A.J.S.; Cehlár, M.; Stempniak, M.; Sobik, L. Thermal Imaging Study to Determine the Operational Condition of a Conveyor Belt Drive System Structure. Energies 2021, 14, 3258. [CrossRef]

13. Grzesiek, A.; Zimroz, R.; Śliwiński, P.; Gomolla, N.; Wyłomańska, A. A Method for Structure Breaking Point Detection in Engine Oil Pressure Data. Energies 2021, 14, 5496. [CrossRef]

14. Bazaluk, O.; Velychkovych, A.; Ropyak, L.; Pashechko, M.; Pryhorovska, T.; Lozynskyi, V. Influence of Heavy Weight Drill Pipe Material and Drill Bit Manufacturing Errors on Stress State of Steel Blades. Energies 2021, 14, 4198. [CrossRef]

15. Bazaluk, O.; Slabyi, O.; Vekeryk, V.; Velychkovych, A.; Ropyak, L.; Lozynskyi, V. A Technology of Hydrocarbon Fluid Production Intensification by Productive Stratum Drainage Zone Reaming. Energies 2021, 14, 3514. [CrossRef]

16. Janus, J.; Krawczyk, J. Measurement and Simulation of Flow in a Section of a Mine Gallery. Energies 2021, 14, 4894. [CrossRef]

17. Adach-Pawelus, K.; Pawelus, D. Influence of Driving Direction on the Stability of a Group of Headings Located in a Field of High Horizontal Stresses in the Polish Underground Copper Mines. Energies 2021, 14, 5955. [CrossRef]

18. Wajs, J.; Trybała, P.; Górniak-Zimroz, J.; Krupa-Kurzynowska, J.; Kasza, D. Modern Solution for Fast and Accurate Inventorization of Open-Pit Mines by the Active Remote Sensing Technique-Case Study of Mikoszów Granite Mine (Lower Silesia, SW Poland). Energies 2021, 14, 6853. [CrossRef]

19. Wodecki, J.; Góralczyk, M.; Krot, P.; Ziętek, B.; Szrek, J.; Worsa-Kozak, M.; Zimroz, R.; Śliwiński, P.; Czajkowski, A. Process Monitoring in Heavy Duty Drilling Rigs—Data Acquisition System and Cycle Identification Algorithms. Energies 2020, 13, 6748. [CrossRef]

20. Borkowski, P.J. Comminution of Copper Ores with the Use of a High-Pressure Water Jet. Energies 2020, 13, 6274. [CrossRef]

21. Pactwa, K.; Konieczna-Fuławka, M.; Fuławka, K.; Aro, P.; Jaśkiewicz-Proć, I.; Kozłowska-Woszczycka, A. Second Life of PostMining Infrastructure in Light of the Circular Economy and Sustainable Development-Recent Advances and Perspectives. Energies 2021, 14, 7551. [CrossRef]

22. Tutak, M.; Brodny, J.; Szurgacz, D.; Sobik, L.; Zhironkin, S. The Impact of the Ventilation System on the Methane Release Hazard and Spontaneous Combustion of Coal in the Area of Exploitation-A Case Study. Energies 2020, 13, 4891. [CrossRef]

23. Ziętek, B.; Banasiewicz, A.; Zimroz, R.; Szrek, J.; Gola, S. A Portable Environmental Data-Monitoring System for Air Hazard Evaluation in Deep Underground Mines. Energies 2020, 13, 6331. [CrossRef]

24. Zimroz, P.; Trybała, P.; Wróblewski, A.; Góralczyk, M.; Szrek, J.; Wójcik, A.; Zimroz, R. Application of UAV in Search and Rescue Actions in Underground Mine-A Specific Sound Detection in Noisy Acoustic Signal. Energies 2021, 14, 3725. [CrossRef]

25. Dwornik, M.; Porzycka-Strzelczyk, S.; Strzelczyk, J.; Malik, H.; Murdzek, R.; Franczyk, A.; Bała, J. Automatic Detection of Subsidence Troughs in SAR Interferograms using Mathematical Morphology. Energies 2021, 14, 7785. [CrossRef] 